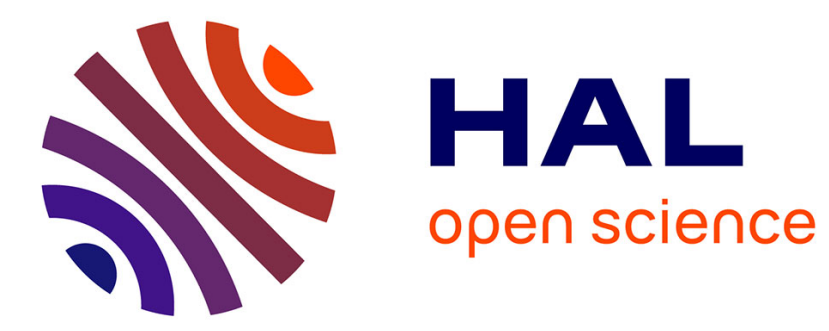

\title{
Risk-targeted seismic design maps for mainland France
} John Douglas, Thomas Ulrich, Caterina Negulescu

\section{To cite this version:}

John Douglas, Thomas Ulrich, Caterina Negulescu. Risk-targeted seismic design maps for mainland France. Natural Hazards, 2013, 65 (3), pp.1999-2013. 10.1007/s11069-012-0460-6 . hal-00744513

\section{HAL Id: hal-00744513 https://hal-brgm.archives-ouvertes.fr/hal-00744513}

Submitted on 23 Oct 2012

HAL is a multi-disciplinary open access archive for the deposit and dissemination of scientific research documents, whether they are published or not. The documents may come from teaching and research institutions in France or abroad, or from public or private research centers.
L'archive ouverte pluridisciplinaire HAL, est destinée au dépôt et à la diffusion de documents scientifiques de niveau recherche, publiés ou non, émanant des établissements d'enseignement et de recherche français ou étrangers, des laboratoires publics ou privés. 


\title{
Risk-targeted seismic design maps for mainland France
}

\author{
John Douglas · Thomas Ulrich · Caterina \\ Negulescu
}

Received: date / Accepted: date

\begin{abstract}
In this article the recently proposed approach known as 'risk-targeting' for the development of national seismic design maps is investigated for mainland France. Risktargeting leads to ground-motion maps that, if used for design purposes, would lead to a uniform level of risk nationally. The Eurocode 8 design loads currently in force for France are used as the basis of this study. Because risk-targeting requires various choices on, for example, the level of acceptable risk to be made a priori and these choices are not solely engineering decisions but involve input from decision makers we undertake sensitivity tests to study their influence. It is found that, in contrast to applications of this methodology for US cities, risk-targeting does not lead to large modifications with respect to the national seismic hazard map nor to changes in the relative ranking of cities with respect to their design ground motions. This is because the hazard curves for French cities are almost parallel. In addition, we find that using a target annual collapse probability of about $10^{-5}$ for seismically-designed buildings and a probability of collapse when subjected to the design PGA of $10^{-5}$ leads to reasonable results. This is again in contrast to US studies that have adopted much higher values for both these probabilities.
\end{abstract}

Keywords seismic hazard maps - earthquake risk · France $\cdot$ probabilistic seismic hazard assessment $\cdot$ fragility curves $\cdot$ risk-targeting $\cdot$ collapse rate $\cdot$ acceptable risk

J. Douglas · T. Ulrich $\cdot$ C. Negulescu

RIS/RSI, BRGM, 3 avenue Claude-Guillemin, BP 36009, 45060 Orléans Cedex 2, France 


\section{Introduction}

Like almost all current seismic design maps, the map underlying the French National Annex of the Eurocode 8 (EC8) design code is based on a 'constant hazard' assumption, i.e. the accelerations for design are those for a return period (or alternatively an annual exceedance probability) that is constant across the national territory. As with the majority of design maps (Bommer and Pinho, 2006) the return period for the French National Annex is thought to be 475 years (corresponding to a $10 \%$ probability of exceedance in 50 years), although the return period is not explicitly stated in the document. As discussed by Luco et al (2007), however, it would be more consistent with the final use of seismic design maps to adopt a 'constant risk' assumption in which the design ground motions are defined to lead to a certain level of risk, e.g. annual probability of collapse. This approach was used by the United States Geological Survey (e.g. Luco, 2009) to develop the so-called RiskTargeted Maximum Considered Earthquake $\left(\mathrm{MCE}_{\mathrm{R}}\right)$ ground motions in the ASCE Standard 7-10 and the 2012 edition of the International Building Code (International Code Council, Inc., 2012). Elsewhere the 'risk-targeting' philosophy is called a 'performance-goal based' (United States Nuclear Regulatory Commission, 2007), 'risk-informed' (Konno, 2003) or 'risk-consistent' (Hadjian, 2002) approach. To our knowledge, this idea has not been investigated for the development of national design maps outside the USA. Bommer et al (2005a) propose a more sophisticated approach in which the seismic design levels are fixed based on iterative loss estimation having defined the loss target, but they do not present any calculations using their method. Within the nuclear industry, analyses like that used to develop risk-targeted ground-motion maps for standard structures are becoming widely used, as shown by Kennedy (2011) in relation to the ASCE Standard 43-05. The threshold risk level for nuclear installations, however, is generally lower than targeted for standard structures for the new generation of US seismic design maps.

The aim of this article is to present tests of the risk-targeting procedure of Luco et al (2007) for mainland France (i.e. excluding French overseas departments and territories) using the hazard model developed by Martin et al (2002) and the subsequent map that provides peak ground accelerations (PGA) to define the demand spectrum of the French seismic design code. We investigate whether the current PGA recommendations would require large changes if a risk-targeted approach was adopted. This study is concerned with the definition

of earthquake loading for new structures rather than to define the loading for retrofitting 
or risk analysis of existing buildings. The following section briefly introduces: the French seismic design code, inputs to the subsequent analysis and the method used here to compute earthquake risk. The subsequent section presents the results of the sensitivity tests in which the free input parameters in the analysis are varied. Next, an example map using this approach is presented and compared to the current map. The article ends with a discussion of the results, some conclusions and suggestions for future research.

\section{Computing risk-targeted ground motions}

In 2002 GEO-TER (Géologie Tectonique Environnement et Risques) published a probabilistic seismic hazard assessment (PSHA) for France based on a classic Cornell-McGuire approach (Cornell, 1968; McGuire, 1976) with logic trees (e.g. Kulkarni et al, 1984; Bommer et al, 2005b) to account for epistemic uncertainty (Martin et al, 2002). They presented maps for return periods of 100, 475, 975 and 1975 years. The PGA map for a return period of 475 years was used as the basis for a new seismic zonation following the work of the Groupe d'Études et de Propositions pour la Prévention du risque sismique en France (GEPP) mainly during the period 2002-2004 (e.g. LeBrun et al, 2004). This zonation has recently (1st May 2011) come into application as part of the French National Annex of EC8, the European seismic design code. The main difference between the PSHA maps of GEO-TER and the new French zonation is that the zonation classifies locations into five categories depending on the PGA for 475 years, rather than the continuous values of PGA provided by the original PSHA map. The five classes are: 'très faible' (very low) (PGA $<0.7 \mathrm{~m} / \mathrm{s}^{2}$ ), 'faible' (low) $\left(0.7 \leq \mathrm{PGA}<1.1 \mathrm{~m} / \mathrm{s}^{2}\right)$, 'modéré' (moderate) $\left(1.1 \leq \mathrm{PGA}<1.6 \mathrm{~m} / \mathrm{s}^{2}\right)$, 'moyen' (medium) $\left(1.6 \leq \mathrm{PGA}<3.0 \mathrm{~m} / \mathrm{s}^{2}\right)$ and 'fort' (high) $\left(\mathrm{PGA} \geq 3.0 \mathrm{~m} / \mathrm{s}^{2}\right)^{1}$ (Ministère de l'Écologie, de l'Énergie, du Développement durable et de l'Aménagement du territoire, 2005). The study of Martin et al (2002) and the current seismic zonation are the hazard inputs to this article. As the maps provided by Martin et al (2002) are not sufficient for our purposes, we had to recalculate the hazard using their input parameters. The results of our recalculation are close to those of Martin et al (2002), but not exactly the same, because we did not consider the smoothing branch of the logic tree (weight 20\%) and because we used the 2003 version of the CRISIS PSHA software (rather than the version from 1999 used by GEO-TER).

\footnotetext{
${ }^{1}$ Only islands in the French Antilles (e.g. Guadeloupe and Martinique) are classified in the highest zone.
} 
Two performance levels are considered in EC8: 'no-collapse requirement', which should be met for a reference seismic action with a $10 \%$ probability of exceedance in 50 years (475year return period), and 'damage limitation requirement', which should be met for a seismic action with $50 \%$ probability of exceedance in 50 years (95-year return period). 'No-collapse' means that the structure should: withstand the seismic design action without collapse, retain its integrity and have residual load-bearing capacity after the earthquake. 'Damage limitation' means that the structure should withstand a more frequent seismic action without damage or limitations of use. The probability of collapse associated with designing for the 'no-collapse requirement' is not explicitly given in EC8 [based on the analysis of Luco et al (2007) the new US code ASCE Standard 7-10 does assign a probability to this requirement]. In addition, the seismic actions of EC8 are expressed in terms of the PGA for a return period of 475 years $\left(a_{g R}\right)$, which is used to scale the normalized spectral shape, rather than pseudo-spectral accelerations for 2475-year return period used by current American codes. The PGA for the 'damage limitation requirement' is given as $0.4 a_{g R}$. For structures of high importance (e.g. hospitals) an importance factor is used to increase the design PGA, which is equivalent to lengthening the return period of the design motions.

As shown by Kennedy (2011), for example, the seismic risk, $y\left(a_{0}\right)$, can be obtained by convolving the seismic hazard curve and the fragility curve using either of these equations:

$$
\begin{aligned}
& y\left(a_{0}\right)=-\int_{0}^{\infty} P_{a_{0}}(a) \frac{\mathrm{d} H(a)}{\mathrm{d} a} \mathrm{~d} a \\
& y\left(a_{0}\right)=\int_{0}^{\infty} H(a) \frac{\mathrm{d} P_{a_{0}}(a)}{\mathrm{d} a} \mathrm{~d} a
\end{aligned}
$$

where $P_{a_{0}}(a)$ is the fragility curve, i.e. the conditional probability of failure given the ground motion level $a$, for a design level of $a_{0}$ and $H(a)$ is the seismic hazard curve, i.e. the exceedance frequency corresponding to ground motion level $a$. In the following, we consider the seismic risk $y\left(a_{0}\right)$ to correspond to the annual probability of collapse of a given structure, as also considered by Luco et al (2007). As part of this study, we have computed $y\left(a_{0}\right)$ using both equations and, as expected, they give the same result. We prefer Equation 2, as did Luco et al (2007), which uses the derivative of the fragility curve, rather than Equation 1, using the derivative of the hazard curve. This is because the hazard is generally only computed in PSHA for a limited number of ground-motion (e.g. PGA) levels and, therefore, its derivative is less accurate than the derivative of a fragility curve, which is typically defined by an analytical equation. It is common to use the lognormal distribution, 
which is completely defined by its mean $\mu$ and standard deviation $\beta$, for fragility curves, i.e. $P(a)=\Phi\{[\ln (a)-\ln (\mu)] / \beta\}$. Luco et al (2007) use this equation for their analysis. Using Equations 1 or 2, the hazard curve from PSHA and estimates of $\mu$ and $\beta$, the annual probability of collapse can be readily computed. The evaluation of this integral is the basis of risk targeting.

To derive a risk-targeted design map, firstly the hazard curves for each site are derived by PSHA in the standard way. Next the desired annual probability of collapse $(Y)$, which defines the acceptable risk threshold, is chosen. The design acceleration is then determined iteratively. At step $i$, the fragility curve for typical buildings is defined by the trial design PGA $\left(a_{i}\right)$, conditional probability of collapse $(X)$ for $a_{i}$ and the standard deviation $\beta$ (a lognormal fragility curve is fully defined by the relation $P_{a_{0}}\left(a_{0}\right)=X$ if the standard deviation is fixed). For this value of $a_{i}$ the risk integral is computed for the considered site to find $y\left(a_{i}\right)$. Then, examining the value of $Y-y\left(a_{i}\right), a_{i+1}$ is generated for the next iteration. The procedure is then repeated until $\left(a_{n}\right)$ converges. This iterative method is used for every location covered by the map. The risk integral takes into account the whole hazard curve rather than simply basing the design ground motions on the PGA for a given return period. Consequently, the slopes of the hazard curves for each site have a large impact on the results: the relative ranking in design PGA for sites with parallel hazard curves would not change and only when hazard curves have different slopes could their ranking change, by adopting a risk-targeted approach.

The elegance of using knowledge of the level of risk to define the design ground motions comes at the cost of introducing various input parameters in place of a return period for a 'constant hazard' map. The evaluation of this integral requires that the acceptable risk to the population $Y$ be quantified, which is obviously not a solely scientific question as compared to quantifying a constant hazard return period. Both are partly social questions, which might require input from politicians and sociologists, for example. The integral also requires the fragility curve for a building designed to the design code with, if assuming a lognormal distribution, its parameters $\mu$ (or alternatively $X$ ) and $\beta$, which are civil engineering questions. In the documentation accompanying the French seismic regulations there is almost no guidance on what value to choose $Y$, or on the intrinsic values of $X$ and $\beta$. The fragility curve (or curves) should, ideally, be based on analyses of typical structures designed using the EC8 regulations. Because the seismic design maps apply to all types of structures covered by the design code, an average curve should be used that takes account of the variability in 
the vulnerability of structures of different materials (e.g. reinforced concrete and steel) and geometries (e.g. different numbers of storeys and bays).

To develop risk-targeted maps for the USA, Luco et al (2007) used fragility curves based on analyses of typical structures designed using the ASCE Standard 7-05 (Federal Emergency Management Agency, 2009). These analyses indicated that there is roughly a $10 \%$ chance that any structure will experience partial or total collapse as a result of its mapped design ground motion (Luco et al, 2007). Consequently Luco et al (2007) used the equivalent of $P(\mathrm{PGA})=0.1$. Luco et al (2007) adopted a standard deviation $\beta$ for their fragility curves of 0.8 and Chapter 21 of the ASCE Standard 7-10 specifies 0.6 for its sitespecific ground-motion procedures for seismic design.

EC8 does not provide nor discuss fragility curves for structures designed using this building code. The development of such curves for the purposes of developing risk-targeted ground motions requires the design of many structures for different levels of ground motion as indicated by the National Annex and different geometries and materials. Subsequently the fragility of these structures could be evaluated using finite-element codes and various levels of shaking (e.g. Seyedi et al, 2010). To our knowledge such calculations have not been made and fragility curves for EC8-designed structures have not been published. Therefore, we base our fragility curves on those used by Luco et al (2007) but we acknowledge the uncertainty in this choice. Because of the uncertainty in all input variables, in the following section we undertake a number of sensitivity analyses.

\section{Sensitivity tests}

A series of sensitivity tests are conducted for these French cities with increasing level of seismic hazard: Paris (lowest zone), Lyon, Nantes, Nice, and Grenoble and Lourdes (highest zone in mainland France) (Figure 1), to assess the annual probabilities of collapse, $y$, resulting from the hazard map currently defined in the French National Annex of Eurocode 8. The seismic hazard curves for the six selected cities using the hazard model of Martin et al (2002) are displayed in Figure 2. Due to the lack of fragility curves specifically for structures designed using Eurocode 8, various values of $X$ and standard deviation of curves following the lognormal distribution were used. The results of these analyses are summarized in Table 1 . From this table the sensitivity of $y$ to the parameters $X$ and $\beta$, for the 475 -year design PGA, can be seen. This sensitivity is more clearly seen in Figure 3 where $y$ is plotted against 
$X$ for various values of $\beta$ and two example French cities. In the following sections we try to choose appropriate values of the desired annual probability of collapse $(Y)$ based on our calculations, the available literature and engineering arguments.

[Fig. 1 about here.]

[Fig. 2 about here.]

[Fig. 3 about here.]

\subsection{Fragility curves}

The value of $\beta$ has a large effect on the fragility curves, since we are constraining the probability of collapse $X$ for a design PGA with a 475-year return period, which should be a small value. Table 1 shows that when $\beta$ is high [e.g. 0.8, the value adopted by Luco et al (2007) when constraining for a design ground motion with a return period of roughly 2475 years] and $X$ is low the corresponding fragility curve is unrealistic since it predicts low collapse probabilities even for very high shaking levels (high values of $\mu$ ). Based on this table and the values of $\beta$ reported by Crowley et al (2011) for reinforced-concrete buildings classified into generic classes (e.g. 'mid-rise (4-to-7 storeys) seismically-designed'), which are around 0.5 , we prefer to use 0.5 for this parameter, in contrast to 0.8 used by Luco et al (2007) but relatively consistent with the 0.6 specified in the ASCE Standard 7-10. Even using $\beta=0.5$ the values of $\mu$ for the 'medium' zone are still possibly unrealistically high when $X$ is small. This suggests that a high value of $X$ (e.g. $10^{-4}$ ) should be used. Figure 3 shows that the annual probability of collapse $y$ and $X$ are linked (if only small changes in the design ground motions based on a 475-year return period are desired) and, therefore, if $X$ was large $y$ would also need to increase to a unrealistically high value (see next section).

3.2 Target annual probability of collapse, $Y$

The choice of a target annual probability of collapse, $Y$, is discussed by Luco et al (2007) for the USA. Analogous to what we have done, they computed the probabilities of collapse resulting from the design maps in ASCE Standard 7-05 using the methodology presented above, $P(\mathrm{PGA})=0.1, \beta=0.8$ and the current seismic hazard curves. They obtained an 
average value for western USA of $1 \%$ in 50 years $\left(Y=2 \times 10^{-4}\right)$, which they then adopted as the risk target nationwide. Fajfar and Dolšek (2012) and Goulet et al (2007) evaluate the failure probabilities of code-designed structures using two different approaches and find similar probabilities to that used by Luco et al (2007).

Labbé (2010) tries to estimate the annual probability of collapse in mainland France with inputs from the French historical earthquake catalogue (BRGM-IRSN-EDF, 2011). Using a simple approach, he computes the mean areas affected annually by intensity higher than V on the European Macroseismic Scale (EMS98) (Grünthal, 2001). From this he deduces the average probability of damage of grades 2 and 3 (moderate to significant damage) using the EMS98, which are about $10^{-4}$ for grade 2 and about $10^{-5}$ for grade 3 . Partial collapse, which is of interest here, corresponds to grade 4, and can be estimated at about $10^{-6}$ but caution should be used when interpreting this value because of the simplified methodology of Labbé (2010).

Kennedy (2011) computes the minimum seismic core damage frequency (SCDF) achieved at 28 nuclear power plants in the central and eastern USA when the site specific design response spectra for safe shutdown earthquakes are defined by state-of-the-art approaches. The minimum SCDF lies in the range of less than $6 \times 10^{-6}$ to $0.6 \times 10^{-6}$ per annum with a median of about $3 \times 10^{-6}$ per annum. Based partly on the analysis of Kennedy (2011), the target SCDF in United States Nuclear Regulatory Commission (2007) is $10^{-5}$. These values are of a similar order to those suggested for normal buildings by Labbé (2010) (and adopted here, see below), even though it could be argued that the consequences of an accident at a nuclear reactor are much higher than that associated with the collapse of a regular structure and, therefore, a lower risk target should be sought for nuclear facilities.

Based on a review of the literature and design codes, Duckett (2004) recommends that for accidental loads the engineer should aim for a risk of failure of roughly $10^{-6}$ per annum but following a cost-benefit analysis and after consultation with the relevant authorities this could be increased up to $10^{-4}$ per annum. He notes, however, that the public may accept higher risk levels for accidental loading, which cannot by definition be forecast, than for loading, such as earthquakes, that could be expected.

Based on simple reasoning, we believe the value used for risk-targeting in the USA is much too high. For example, assuming a $1 \%$ chance in 50 years and 1 million buildings (a rough number for areas within the 'moderate' and 'medium' hazard zones of France) we would have on average 200 collapsed buildings due to earthquakes per year, which seems 
much too high. As a compromise between roughly $10^{-4}$ adopted by Luco et al (2007) and computed by Fajfar and Dolšek (2012), and Goulet et al (2007) and $10^{-6}$ suggested by Labbé (2010), Duckett (2004) and Kennedy (2011), we adopt $Y=10^{-5}$ for subsequent analysis. This value also means that the fragility curves for the selected value of $\beta=0.5$ do not imply unrealistically strong buildings (i.e. the values of $\mu$ in Table 1 are quite small).

\subsection{Probability of collapse at design PGA, $X$}

The design PGAs used in Table 1 to define the fragility curves have been taken from the French seismic zoning, and are consequently based on ground motions computed for a 475year return period. Hence, we should not use the same value for $X$ as the one used by Luco et al (2007), which is based on accelerations at around a 2475-year return period, but instead we should use a lower value. After assuming $\beta=0.5$ and $Y=10^{-5}$, Figure 3 and Table 1 show that $X$ must be defined as around $10^{-5}$ if large changes in the design PGAs (relative to 475 -year accelerations) are not desired. Therefore, $X=10^{-5}$ has been used here for subsequent analyses.

It is interesting to compare the values of $X$ and $y$ computed for mainland France and for United States. Luco et al (2007) based their fragility curves on pseudo-spectral accelerations (PSA) at $0.2 \mathrm{~s}$ computed for a 2475 -year return period and $P_{\mathrm{PSA}(0.2 \mathrm{~s})}[\operatorname{PSA}(0.2 \mathrm{~s})]=0.1$. Table 2 shows $X(2475 y)$ computed for various cities in mainland France and the corresponding $y$, for various values of $\beta$. Using the same $\beta$ and targeting the same $Y$ as Luco et al (2007) ( $Y=2 \times 10^{-4}$ and $\beta=0.8$ ) leads to a lower value of $X(2475 y)$ (0.018) compared to Luco et al (2007) (0.1). The value that is assumed for $X(2475 y)$ is actually arbitrary because it simply defines which percentile of the fragility curve is fixed by the seismic design code. We assume $X=10^{-5}$ for a return period of 475 years because this leads to only minor modifications in the design PGAs for most locations in mainland France. This assumption means that application of the design levels defined by Eurocode 8 for France would lead to buildings with very small chances of collapse when subjected to their design loads.

\subsection{Effect of using acceleration bands}

Using ranges of acceleration rather than the exact PGA values for a 475-year return period computed by Martin et al (2002) has a significant impact on the results. Table 3 illustrates 
that using the upper and lower limits of the EC8 acceleration levels can change the level of risk by one order of magnitude. Therefore, for the ground-motion maps associated with future design codes, banding perhaps should not be used but the original PGAs presented. This is especially true if a risk-targeting approach is used because the use of bands would reduce some of the benefits of the method.

\section{Risk-targeted seismic design maps for mainland France}

The risk-targeting approach can produce risk-constant acceleration maps, by back-calculating iteratively the accelerations constraining the fragility functions, after having fixed $X, Y$ and $\beta$. Hence, if the annual probability of collapse computed with the trial design acceleration is higher than the targeted value, we have to increase the design acceleration (thereby, enforcing stronger structures) and vice versa. Table 4 summarizes the results obtained using this iterative procedure for the six cities.

It can be noticed that the accelerations computed with this approach are close to those on the current hazard map. This is what we expected because the slopes of the hazard curves (see values of $k$ in Table 1) are quite similar over the national territory and the value of $X$ was assumed such that it does not modify greatly the current design PGAs when $Y=10^{-5}$ and $\beta=0.5$. The PGAs from the risk-targeting approach are generally slightly lower than those given on the current hazard map since they generally correspond to a return period shorter than 475 years. As an example, the seismic design map of mainland France derived by targeting a risk of $Y=10^{-5}$ with $X=10^{-5}$ and $\beta=0.5$ is shown in Figure 4.

[Fig. 4 about here.]

Comparing Figures 1 (the current seismic zonation) and 4 shows that the effect of risktargeting on the design PGAs is limited and the relative ranking of French locations would not greatly alter by adopting a risk-targeted approach. The ratio between these two maps is shown in Figure 5 - ASCE Standard 7-10 calls this ratio the risk coefficient. Locations of the highest hazard (e.g. Lourdes) would see their design PGAs reduced and the PGAs in areas with the lowest hazard (e.g. Paris) would increase. If a similar procedure to that followed in producing the current French National Annex, i.e. classifying locations into a handful of broad acceleration categories, was adopted for risk-targeted maps then most of the apparent differences between the maps shown on Figures 1 and 4 would disappear. This 
is encouraging because it is important that the hazard levels do not change greatly from one generation of building code to the next so that buildings do not need significant retrofitting and that the loading conditions used by engineers are stable in time.

[Fig. 5 about here.]

$k$ is roughly uniform across mainland France (about 4). This compares to 3-4 for western North America and to 1-2 for eastern North America (e.g. Ellingwood and Kinali, 2009) and a value of 3 recommended in the French National Annex of Eurocode 8 to modify the PGA for a 475-year return period to a different return period. This uniformity in $k$ between locations in mainland France means that the effect of risk targeting on the relative ranking of French cities is limited. This contrasts with the findings for the western and eastern US, where the risk-targeted approach has been adopted to avoid surprising results when a uniform (and long) return period is used (Luco et al, 2007).

\section{Discussion}

Rather than using the risk of collapse to define the acceptable risk level it may be more appropriate for countries of moderate seismicity, such as mainland France, if the risk target is defined in terms of the probability of slight damage, for example. Because of the nature of fragility curves and the observed distribution of earthquake damage, targeting the risk of a certain level of damage (e.g. collapse) roughly implies a risk target in terms of other damage levels too (e.g. if one building collapses, one hundred others may suffer slight damage). The cost of each damage level could be quantified and then the annual cost of earthquake damage computed to facilitate the choice of what risk is acceptable. This is similar to the idea of Bommer et al (2005a) but less sophisticated.

As shown above, the acceptable risk target for collapse can be bracketed by arguments based on the observed rate of collapse in earthquakes and by comparisons to acceptable risks for other industries, for example. However, the other required value for risk targeting, $X$, the probability of collapse when a building designed to the seismic design code is subjected to the mapped ground motion, is a more difficult parameter to constrain since it is associated with the conservatism of the design code, which is almost never quantified. As also shown above, though, if large changes in the design ground motions are not desired, then once $Y$ is chosen (or $X$ is quantified) the necessary assumption for $X$ (or choice for $Y$ ) follows almost automatically. 
For this article we have focused on providing a single ground-motion map for all types of structures covered by the EC8 design code (e.g. reinforced concrete and steel structures of various geometries), which is the current approach for expressing seismic loading in the majority of design codes. This means that for risk-targeting the fragility curves used must be sufficiently generic to cover the vulnerability of a large range of different buildings and $\beta$ must capture this spread of vulnerabilities. This is in contrast to the fragility curves used for risk analysis of nuclear reactors, for example, where $\beta$ is quite small since it does not need to account for the variability in response due to different building types or geometries. If future design codes adopted an approach where multiple ground-motion maps for different types of structures were acceptable, or their design procedures resulted in similar fragility curves for different types of structures, then more specific fragility curves could be used.

It also should be noted that this article is concerned with ground-motion maps to be used to define the earthquake loading for new structures rather than to define the loading for retrofitting of existing buildings or for risk assessments of such constructions. Like many European countries a large number of buildings date from before previous French seismic design codes and, therefore, they were not explicitly designed against earthquake loading, even if they will likely have some inherent resistance to minor shaking.

\section{Conclusions}

In this article we have applied the risk-targeting approach to the development of national seismic design maps for mainland France. We find that, by adopting reasonable values for the free input parameters, the maps produced are roughly in line with those currently in force. Before the risk-targeting approach can be routinely used, however, it is necessary to better constrain the free input parameters in this method. In particular, there is considerable uncertainty in appropriate fragility curves for a suite of buildings designed according to EC8, including the conditional probability of collapse when a building is subjected to its design load. Furthermore, what values should be used for the key parameter of desired annual probability of collapse is not simply a civil engineering issue. It should ideally involve input from the wider community (e.g. decision makers) as to what level of earthquake risk is acceptable. 
Acknowledgements We thank Evelyne Foerster and Kushan Wijesundara for useful discussions on various aspects of this study and Nicolas Luco and Peter Fajfar for answering our questions on the targeted annual collapse rate. This article was supported by an internal BRGM research programme (VULNERISK/MULTIRISK 2011). We thank the anonymous reviewers for their comments on an earlier version of this article.

\section{References}

Bommer JJ, Pinho R (2006) Adapting earthquake actions in Eurocode 8 for performancebased seismic design. Earthquake Engineering and Structural Dynamics 35(1):39-55, DOI 10.1002/eqe.530

Bommer JJ, Pinho R, Crowley H (2005a) Using displacement-based earthquake loss assessment in the selection of seismic code design levels. In: Proceedings of International Conference on Structural Safety and Reliability (ICOSSAR ’05), pp 3567-3574

Bommer JJ, Scherbaum F, Bungum H, Cotton F, Sabetta F, Abrahamson NA (2005b) On the use of logic trees for ground-motion prediction equations in seismic-hazard analysis. Bulletin of the Seismological Society of America 95(2):377-389, DOI 10.1785/0120040073

BRGM-IRSN-EDF (2011) SisFrance : Histoire et caractéristiques des séismes ressentis en France. On Internet at www.sisfrance.net/

Cornell CA (1968) Engineering seismic risk analysis. Bulletin of the Seismological Society of America 58(5):1583-1606

Crowley H, Colombi M, Silva V, Ahmad N, Fardis M, Tsionis G, Papailia A, Taucer F, Hancilar U, Yakut A, Erberik MA (2011) D3.1 - Fragility functions for common RC building types in Europe. Tech. rep., Systemic Seismic Vulnerability and Risk Analysis for Buildings, Lifeline Networks and Infrastructures Safety Gain (SYNER-G), Project of the EC Framework Programme 7

Duckett W (2004) Risk analysis and the acceptable probability of failure. In: Henderson Colloquium (British Group of the International Association for Bridge and Structural Engineering)

Ellingwood BR, Kinali K (2009) Quantifying and communicating uncertainty in seismic risk assessment. Structural Safety 31:179-187, DOI 10.1016/j.strusafe.2008.06.001

Fajfar P, Dolšek M (2012) A practice-oriented estimation of the failure probability of building structures. Earthquake Engineering and Structural Dynamics 41(3):531-547, DOI 10.1002/eqe. 1143 
Federal Emergency Management Agency (2009) Quantification of building seismic performance factors. Tech. Rep. FEMA P695, prepared by Applied Technology Council

Goulet CA, Haselton CB, Mitrani-Reiser J, Beck JL, Deierlein GG, Porter KA, Stewart JP (2007) Evaluation of the seismic performance of a code-conforming reinforced-concrete frame building — from seismic hazard to collapse safety and economic losses. Earthquake Engineering and Structural Dynamics 36:1973-1997, DOI 10.1002/eqe.694

Grünthal G (2001) European Macroseismic Scale 1998, vol 19. Cahiers du Centre Européen de Géodynamique et de Séismologie, Luxembourg

Hadjian AH (2002) A general framework for risk-consistent seismic design. Earthquake Engineering and Structural Dynamics 31:601-626, DOI 10.1002/eqe.145

International Code Council, Inc (2012) 2012 International Building Code. International Code Council, Inc., USA

Kennedy RP (2011) Performance-goal based (risk informed) approach for establishing the SSE site specific response spectrum for future nuclear power plants. Nuclear Engineering and Design 241:648-656, DOI 10.1016/j.nucengdes.2010.08.001

Konno T (2003) A developing risk-informed design basis earthquake ground motion methodology. In: Transactions of the 17th International Conference on Structural Mechanics in Reactor Technology (SMiRT 17), Paper \#K11-1

Kulkarni RB, Youngs RR, Coppersmith KJ (1984) Assessment of confidence intervals for results of seismic hazard analysis. In: Proceedings of Eighth World Conference on Earthquake Engineering, vol 1, pp 263-270

Labbé PB (2010) PSHA outputs versus historical seismicity: Example of France. In: Proceedings of Fourteenth European Conference on Earthquake Engineering

LeBrun B, Imbault M, Mouroux P (2004) Participation du BRGM au sous groupe zonage sismique du GEPP: Activité 2003-2004. Rapport intermédiaire BRGM/RP-52970-FR, BRGM, France, in French

Luco N (2009) Preparation of new seismic design maps for building codes. In: 2009 COSMOS Technical Sesssion

Luco N, Ellingwood BR, Hamburger RO, Hooper JD, Kimball JK, Kircher CA (2007) Risk-targeted versus current seismic design maps for the conterminous United States. In: SEAOC 2007 Convention Proceedings

Martin C, Combes P, R S, Lignon G, Fioravanti A, Carbon D, Monge O, Grellet B (2002) Revision du zonage sismique de la France: Etude probabiliste. Tech. Rep. Rapport de 
Phase 3, GEO-TER, France, report GTR/MATE/0701-150, Affaire no. 1601, in French

McGuire RK (1976) FORTRAN computer program for seismic risk analysis. Open-File Report 76-67, United States Department of the Interior Geological Survey

Ministère de l'Écologie, de l'Énergie, du Développement durable et de l'Aménagement du territoire (2005) Aléa sismique de la France. Poster and on Internet at: www.planseisme.fr/La-nouvelle-carte-d-alea-sismique.html

Seyedi DM, Gehl P, Douglas J, Davenne L, Mezher N, Ghavamian S (2010) Development of seismic fragility surfaces for reinforced concrete buildings by means of nonlinear timehistory analysis. Earthquake Engineering and Structural Dynamics 39(1):91-108, DOI 10.1002/eqe.939

United States Nuclear Regulatory Commission (2007) A performance-based approach to define the site-specific earthquake ground motion. Tech. Rep. 1.208 
Table 1 Annual probability of collapse of structures, $y$, based on the hazard map defined in the French National Annex of EC8. $\beta$ is the standard deviation of the lognormal fragility curves used and $X$ is the probability of collapse for the design PGA $a_{g R}$, given as the range of PGA indicated on the map. PGA (GEO-TER 2002) is the PGA extracted from Martin et al (2002), whereas PGA (recalculated) is the value recalculated for this study. $k$ and $k_{0}$ are the shape parameter (slope) and constant, respectively, of the hazard curve when plotted on a $\log -\log$ graph (e.g. Ellingwood and Kinali, 2009). $\mu$ is the PGA corresponding to a probability of 0.5 of collapse for the fragility curve $P_{a_{g} R}$ for the considered zone. The values of $y[\mathrm{PGA}($ recalculated $)]$ and $X$ in the column 'Average for France' are the mean values for all locations in a grid covering mainland France.

\begin{tabular}{|c|c|c|c|c|c|c|c|c|c|c|}
\hline Average for France & & & Paris & Lyon & Nantes & Nice & Grenoble & Lourdes & \multirow{7}{*}{$\begin{array}{l}P_{a_{g R}} \\
\text { very low } \\
<0.7\end{array}$} & \multirow{2}{*}{$\begin{array}{l}P_{a_{g R}} \\
\text { medium }\end{array}$} \\
\hline Zone & & & very low & low & moderate & moderate & medium & medium & & \\
\hline$a_{g R}$ & \multicolumn{2}{|c|}{$\left(\mathrm{m} / \mathrm{s}^{2}\right)$} & $<0.7$ & $0.7-1.1$ & $1.1-1.6$ & $1.1-1.6$ & $1.6-3.0$ & $1.6-3.0$ & & $1.6-3.0$ \\
\hline PGA (GEO-TER 2002) & \multicolumn{2}{|c|}{$\left(\mathrm{m} / \mathrm{s}^{2}\right)$} & 0.45 & 1.06 & 1.16 & 1.49 & 1.73 & 2.22 & & \\
\hline PGA (recalculated) & \multicolumn{2}{|c|}{$\left(\mathrm{m} / \mathrm{s}^{2}\right)$} & 0.35 & 1.03 & 1.18 & 1.46 & 2.17 & 2.74 & & \\
\hline$k$ & & & 4.8 & 4.7 & 4.4 & 4.0 & 3.8 & 4.1 & & \\
\hline$k_{0} \times 10^{3}$ & & & 1.8 & 15.4 & 15.2 & 20.6 & 65.6 & 184.0 & & \\
\hline$y[\mathrm{PGA}($ recalculated $)]$ & $\beta$ & $X$ & \multicolumn{6}{|c|}{$y[\mathrm{PGA}($ recalculated $)]$} & $\mu$ & $\mu$ \\
\hline $10^{-4}$ & 0.4 & $4.0 \times 10^{-5}$ & $5.7 \times 10^{-5}$ & $1.1 \times 10^{-4}$ & $3.4 \times 10^{-5}$ & $7.2 \times 10^{-5}$ & $7.6 \times 10^{-5}$ & $1.4 \times 10^{-4}$ & 1.9 & 7.8 \\
\hline$"$ & 0.5 & $3.0 \times 10^{-4}$ & $5.3 \times 10^{-5}$ & $1.1 \times 10^{-4}$ & $3.6 \times 10^{-5}$ & $7.4 \times 10^{-5}$ & $7.8 \times 10^{-5}$ & $1.4 \times 10^{-4}$ & 2.2 & 8.9 \\
\hline$"$ & 0.6 & $9.0 \times 10^{-4}$ & $4.9 \times 10^{-5}$ & $1.2 \times 10^{-4}$ & $3.8 \times 10^{-5}$ & $7.7 \times 10^{-5}$ & $8.0 \times 10^{-5}$ & $1.5 \times 10^{-4}$ & 2.6 & 10.4 \\
\hline$"$ & 0.8 & $2.5 \times 10^{-3}$ & $4.5 \times 10^{-5}$ & $1.2 \times 10^{-4}$ & $4.4 \times 10^{-5}$ & $8.6 \times 10^{-5}$ & $8.6 \times 10^{-5}$ & $1.7 \times 10^{-4}$ & 3.8 & 15.1 \\
\hline$"$ & 1 & $3.4 \times 10^{-3}$ & $4.1 \times 10^{-5}$ & $1.2 \times 10^{-4}$ & $4.8 \times 10^{-5}$ & $9.1 \times 10^{-5}$ & $8.7 \times 10^{-5}$ & $1.8 \times 10^{-4}$ & 6.0 & 24.0 \\
\hline $10^{-5}$ & 0.3 & $5.0 \times 10^{-13}$ & $7.9 \times 10^{-6}$ & $9.1 \times 10^{-6}$ & $1.9 \times 10^{-6}$ & $4.9 \times 10^{-6}$ & $3.1 \times 10^{-6}$ & $4.8 \times 10^{-6}$ & 3.3 & 13.2 \\
\hline$"$ & 0.4 & $8.0 \times 10^{-9}$ & $7.5 \times 10^{-6}$ & $9.5 \times 10^{-6}$ & $2.1 \times 10^{-6}$ & $5.3 \times 10^{-6}$ & $4.1 \times 10^{-6}$ & $6.6 \times 10^{-6}$ & 3.8 & 15.3 \\
\hline " & 0.5 & $7.0 \times 10^{-7}$ & $7.0 \times 10^{-6}$ & $9.9 \times 10^{-6}$ & $2.4 \times 10^{-6}$ & $5.7 \times 10^{-6}$ & $5.0 \times 10^{-6}$ & $8.4 \times 10^{-6}$ & 4.5 & 17.9 \\
\hline " & 0.6 & $8.0 \times 10^{-6}$ & $6.6 \times 10^{-6}$ & $1.0 \times 10^{-5}$ & $2.8 \times 10^{-6}$ & $6.2 \times 10^{-6}$ & $5.9 \times 10^{-6}$ & $1.0 \times 10^{-5}$ & 5.3 & 21.3 \\
\hline " & 0.8 & $8.0 \times 10^{-5}$ & $5.7 \times 10^{-6}$ & $1.1 \times 10^{-5}$ & $3.5 \times 10^{-6}$ & $7.3 \times 10^{-6}$ & $7.3 \times 10^{-6}$ & $1.4 \times 10^{-5}$ & 8.2 & 32.8 \\
\hline " & 1 & $2.0 \times 10^{-4}$ & $4.9 \times 10^{-6}$ & $1.2 \times 10^{-5}$ & $4.1 \times 10^{-6}$ & $8.1 \times 10^{-6}$ & $8.0 \times 10^{-6}$ & $1.6 \times 10^{-5}$ & 13.8 & 55.2 \\
\hline $10^{-6}$ & 0.2 & $4.0 \times 10^{-38}$ & $1.0 \times 10^{-6}$ & $7.3 \times 10^{-7}$ & $7.0 \times 10^{-8}$ & $2.1 \times 10^{-7}$ & $3.2 \times 10^{-8}$ & $4.7 \times 10^{-8}$ & 5.2 & 20.9 \\
\hline$"$ & 0.3 & $2.0 \times 10^{-19}$ & $1.1 \times 10^{-6}$ & $7.1 \times 10^{-7}$ & $3.0 \times 10^{-8}$ & $9.2 \times 10^{-8}$ & $1.2 \times 10^{-9}$ & $1.7 \times 10^{-9}$ & 5.8 & 23.4 \\
\hline " & 0.4 & $8.0 \times 10^{-13}$ & $9.5 \times 10^{-7}$ & $7.9 \times 10^{-7}$ & $1.1 \times 10^{-7}$ & $3.1 \times 10^{-7}$ & $1.2 \times 10^{-7}$ & $1.7 \times 10^{-7}$ & 6.8 & 27.0 \\
\hline " & 0.5 & $1.0 \times 10^{-9}$ & $9.1 \times 10^{-7}$ & $8.7 \times 10^{-7}$ & $1.5 \times 10^{-7}$ & $4.0 \times 10^{-7}$ & $2.3 \times 10^{-7}$ & $3.6 \times 10^{-7}$ & 8.0 & 32.1 \\
\hline " & 0.6 & $4.0 \times 10^{-8}$ & $8.0 \times 10^{-7}$ & $8.9 \times 10^{-7}$ & $1.8 \times 10^{-7}$ & $4.5 \times 10^{-7}$ & $3.2 \times 10^{-7}$ & $5.3 \times 10^{-7}$ & 10.0 & 40.1 \\
\hline " & 0.8 & $1.8 \times 10^{-6}$ & $7.0 \times 10^{-7}$ & $1.0 \times 10^{-6}$ & $2.6 \times 10^{-7}$ & $5.9 \times 10^{-7}$ & $5.4 \times 10^{-7}$ & $9.4 \times 10^{-7}$ & 16.3 & 65.1 \\
\hline$"$ & 1 & $9.0 \times 10^{-6}$ & $5.9 \times 10^{-7}$ & $1.1 \times 10^{-6}$ & $3.4 \times 10^{-7}$ & $7.0 \times 10^{-7}$ & $6.8 \times 10^{-7}$ & $1.3 \times 10^{-6}$ & 29.1 & 116.6 \\
\hline
\end{tabular}


Table 2 Annual probability of collapse of structures, $y$, based on PGA computed for a 2475-year return period using hazard curves computed by Martin et al (2002).

\begin{tabular}{|c|c|c|c|c|c|c|c|c|}
\hline Average for France & & & Paris & Lyon & Nantes & Nice & Grenoble & Lourdes \\
\hline PGA(2475y) & $\left(\mathrm{m} / \mathrm{s}^{2}\right)$ & & 0.7 & 1.8 & 2.0 & 2.5 & 3.7 & 4.4 \\
\hline$y[\operatorname{PGA}(2475 y)]$ & $\beta$ & $X(2475 \mathrm{y})$ & \multicolumn{6}{|c|}{$y[\operatorname{PGA}(2475 \mathrm{y})]$} \\
\hline $3.5 \times 10^{-4}$ & 0.8 & 0.100 & $2.0 \times 10^{-4}$ & $2.6 \times 10^{-4}$ & $2.5 \times 10^{-4}$ & $2.7 \times 10^{-4}$ & $2.5 \times 10^{-4}$ & $3.2 \times 10^{-4}$ \\
\hline $2.0 \times 10^{-4}$ & 0.8 & 0.018 & $4.0 \times 10^{-5}$ & $3.9 \times 10^{-5}$ & $3.9 \times 10^{-5}$ & $4.0 \times 10^{-5}$ & $3.7 \times 10^{-5}$ & $4.2 \times 10^{-5}$ \\
\hline $10^{-5}$ & 0.4 & $5.0 \times 10^{-7}$ & $2.6 \times 10^{-6}$ & $5.2 \times 10^{-7}$ & $4.7 \times 10^{-7}$ & $4.2 \times 10^{-7}$ & $1.4 \times 10^{-7}$ & $5.3 \times 10^{-8}$ \\
\hline$"$ & 0.5 & $1.3 \times 10^{-5}$ & $2.6 \times 10^{-6}$ & $6.7 \times 10^{-7}$ & $6.2 \times 10^{-7}$ & $6.0 \times 10^{-7}$ & $3.1 \times 10^{-7}$ & $1.7 \times 10^{-7}$ \\
\hline$"$ & 0.6 & $7.0 \times 10^{-5}$ & $2.5 \times 10^{-6}$ & $8.2 \times 10^{-7}$ & $7.7 \times 10^{-7}$ & $7.6 \times 10^{-7}$ & $5.1 \times 10^{-7}$ & $3.4 \times 10^{-7}$ \\
\hline$"$ & 0.8 & $3.5 \times 10^{-4}$ & $2.4 \times 10^{-6}$ & $1.2 \times 10^{-6}$ & $1.2 \times 10^{-6}$ & $1.2 \times 10^{-6}$ & $9.8 \times 10^{-7}$ & $8.6 \times 10^{-7}$ \\
\hline
\end{tabular}


Table 3 Influence of the use of ranges of acceleration instead of exact value for 475-year return period. The first part of this table shows the three acceleration levels used for constraining the fragility curve in $\mathrm{m} / \mathrm{s}^{2}$ : lower limit of the interval, exact value and upper limit. The second part shows $y$ computed from these three acceleration levels. $X=10^{-5}$ and $\beta=0.5$ have been used.

\begin{tabular}{llllllll}
\hline & Paris & Lyon & Nantes & Nice & Grenoble & Lourdes & Average (France) \\
\hline$a_{g R}$ (lower limit) & none & 0.7 & 1.1 & 1.1 & 1.6 & 1.6 & \\
Exact & 0.35 & 1.03 & 1.18 & 1.46 & 2.17 & 2.74 & 0.95 \\
$a_{g R}$ (upper limit) & 0.7 & 1.1 & 1.6 & 1.6 & 3.0 & 3.0 & \\
\hline & & \multicolumn{7}{c}{$y$} \\
\hline$a_{g R}$ (lower limit) & none & $9.9 \times 10^{-6}$ & $2.4 \times 10^{-6}$ & $5.7 \times 10^{-6}$ & $5.0 \times 10^{-6}$ & $8.4 \times 10^{-6}$ & $1.0 \times 10^{-5}$ \\
Exact & $1.1 \times 10^{-5}$ & $2.1 \times 10^{-6}$ & $1.8 \times 10^{-6}$ & $1.7 \times 10^{-6}$ & $1.1 \times 10^{-6}$ & $4.9 \times 10^{-7}$ & $6.9 \times 10^{-5}$ \\
$a_{g R}$ (upper limit) & $1.0 \times 10^{-6}$ & $1.6 \times 10^{-6}$ & $4.4 \times 10^{-7}$ & $1.1 \times 10^{-6}$ & $1.8 \times 10^{-7}$ & $2.8 \times 10^{-7}$ & $1.5 \times 10^{-6}$ \\
\hline
\end{tabular}


Table 4 Accelerations adjusted iteratively to obtain $Y=10^{-5}$ with $X=10^{-5}$ and $\beta=0.5$. The accelerations from the French zoning map and the exact accelerations for a 475-year return period hazard are also given for comparison. All accelerations are expressed in $\mathrm{m} / \mathrm{s}^{2}$. Also given are the return periods corresponding to these design PGAs

\begin{tabular}{lllllll}
\hline & Paris & Lyon & Nantes & Nice & Grenoble & Lourdes \\
\hline$a_{g R}$ (lower limit) & none & 0.7 & 1.1 & 1.1 & 1.6 & 1.6 \\
Exact & 0.35 & 1.03 & 1.18 & 1.46 & 2.17 & 2.74 \\
$a_{g R}$ (upper limit) & 0.7 & 1.1 & 1.6 & 1.6 & 3.0 & 3.0 \\
\hline PGA & 0.47 & 0.92 & 1.02 & 1.26 & 1.81 & 2.04 \\
Return period (years) & 911 & 343 & 320 & 310 & 294 & 198 \\
\hline
\end{tabular}




\section{List of Figures}

1 French National Seismic Hazard Map (Ministère de l'Écologie, de l'Énergie, du Développement durable et de l'Aménagement du territoire, 2005) and the locations of the six cities chosen for this study.

2 Seismic hazard curves for the six cities selected for this study. The two dashed lines indicate return periods of 475 and 2475 years. Also shown are slopes in $\log -\log$ space of $k=1,2,3$ and $4 \ldots \ldots 22$

$3 y$ against $X$ computed for two French cities and the average for France and various values of $\beta$ (see Table 1 ). . . . . . . . . . . . . 23

4 Seismic design map for mainland France derived by targeting a risk of collapse of $Y=10^{-5}$ with $X=10^{-5}$ and $\beta=0.5 \ldots \ldots 24$

5 Map of risk coefficients (as named by the ASCE Standard 7-10) defined by ratio of map shown in Figures 4 to current seismic zonation shown in Figure 1. 25 


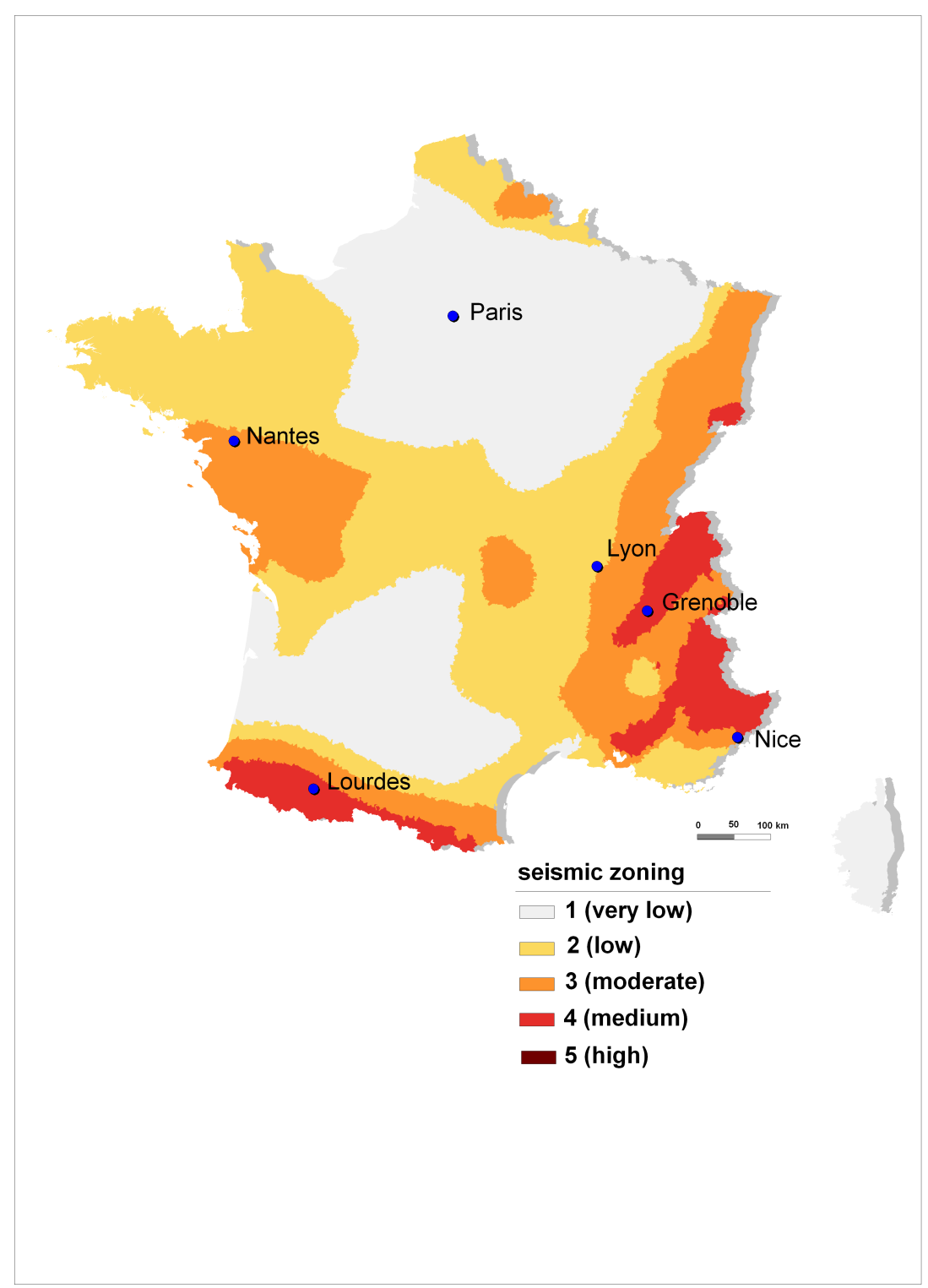

Fig. 1 French National Seismic Hazard Map (Ministère de l'Écologie, de l'Énergie, du Développement durable et de l'Aménagement du territoire, 2005) and the locations of the six cities chosen for this study. 


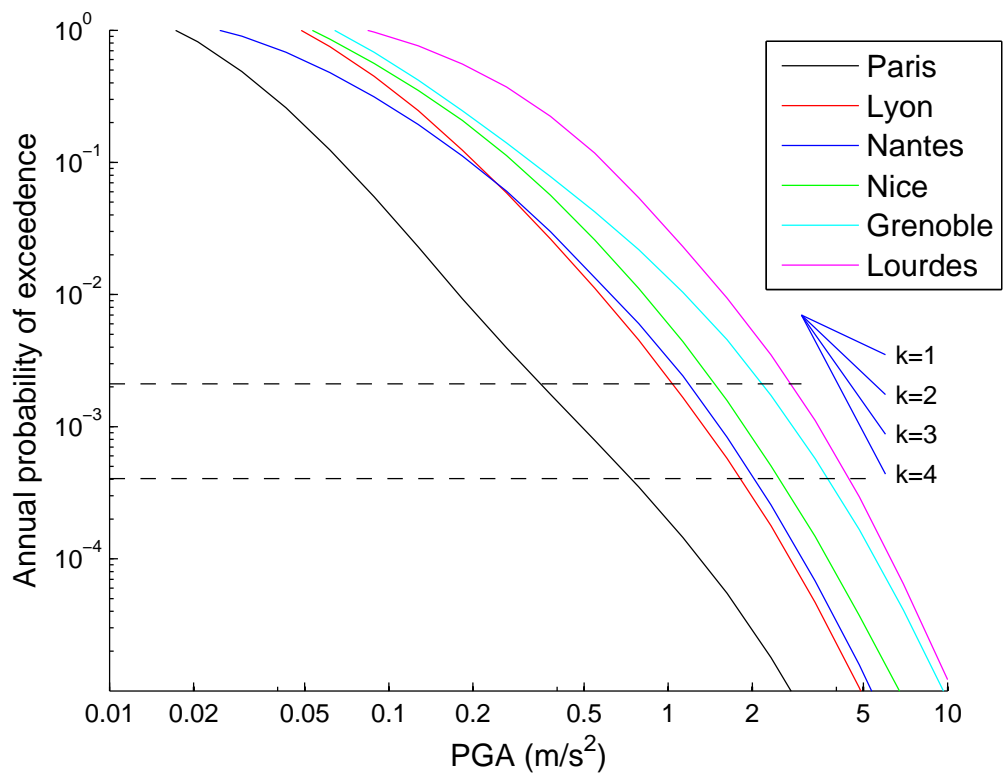

Fig. 2 Seismic hazard curves for the six cities selected for this study. The two dashed lines indicate return periods of 475 and 2475 years. Also shown are slopes in $\log -\log$ space of $k=1,2,3$ and 4. 


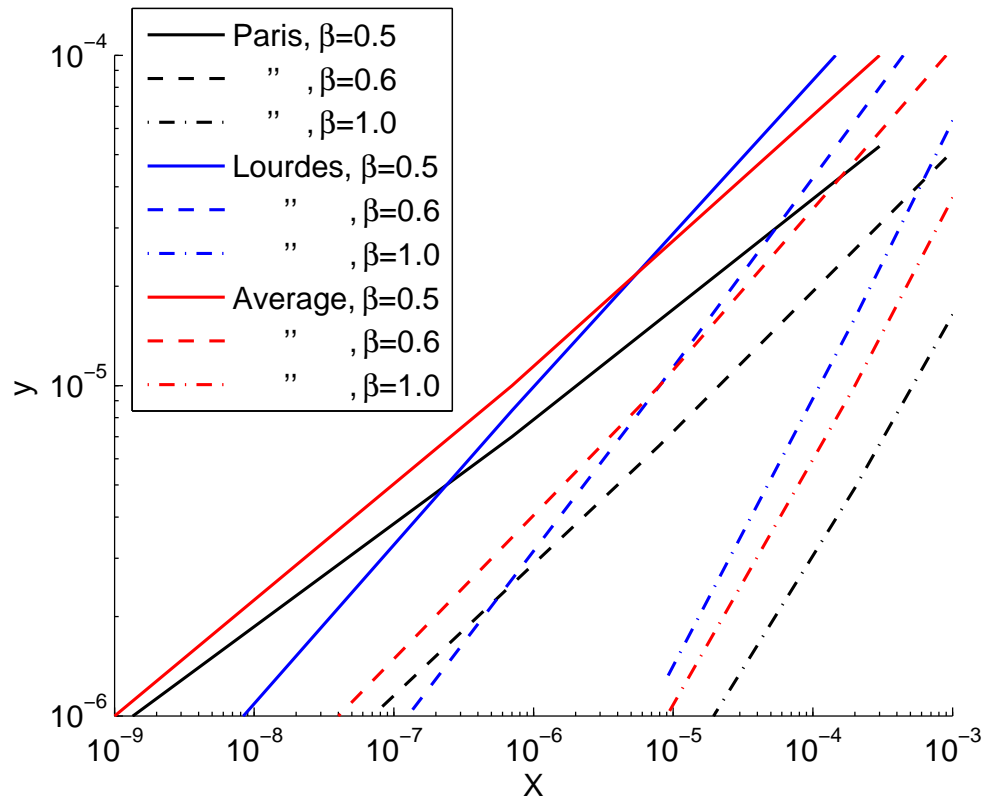

Fig. $3 y$ against $X$ computed for two French cities and the average for France and various values of $\beta$ (see Table 1). 


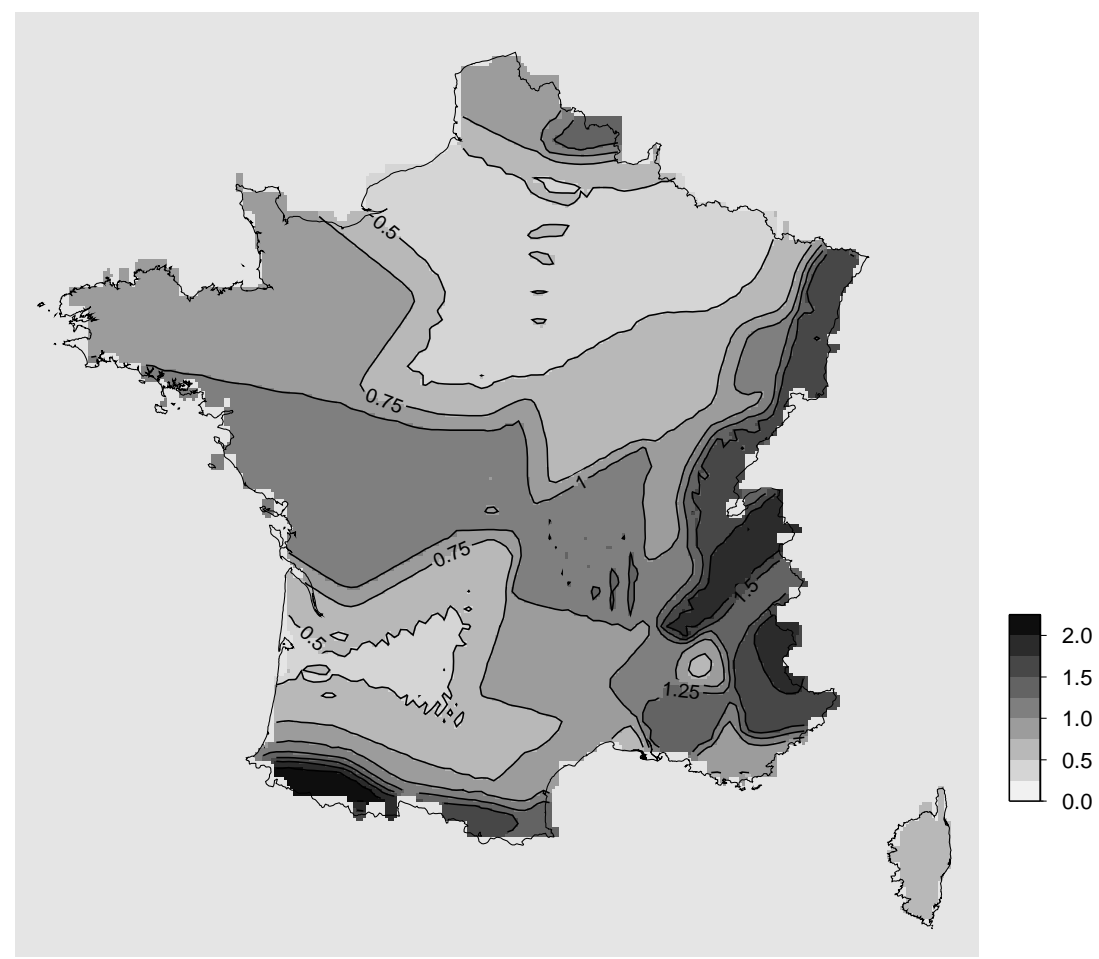

Fig. 4 Seismic design map for mainland France derived by targeting a risk of collapse of $Y=10^{-5}$ with $X=10^{-5}$ and $\beta=0.5$ 


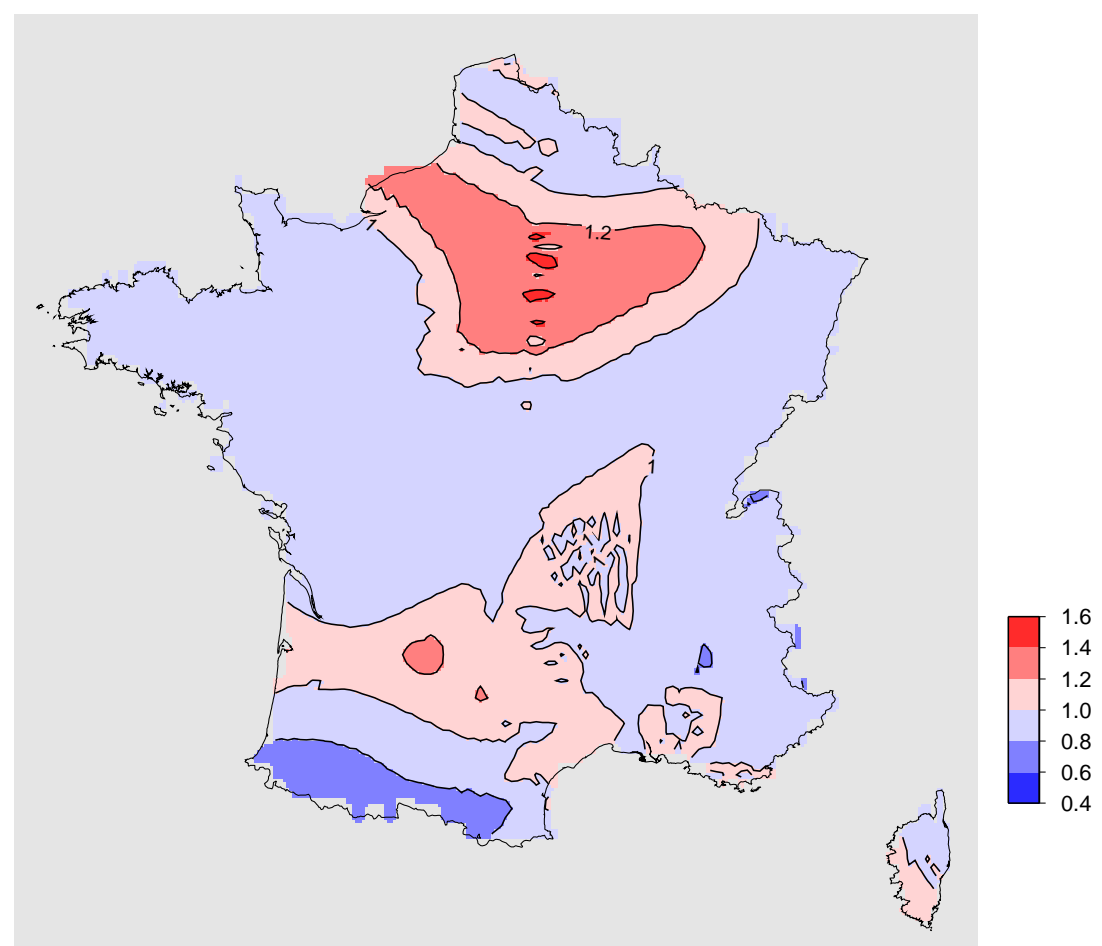

Fig. 5 Map of risk coefficients (as named by the ASCE Standard 7-10) defined by ratio of map shown in Figures 4 to current seismic zonation shown in Figure 1. 